\title{
Estimation of the Interaction Parameter between Polystyrene and Poly ( $p$-chlorostyrene) from Osmotic Pressure Measurements
}

\author{
Etsuyo OGAWA, Noriko YamaguchI, and Miklko SHIMA \\ Tokyo Woman's Christian University, \\ Zempukuji, Suginami-ku, Tokyo 167, Japan
}

(Received June 19, 1986)

\begin{abstract}
The composition dependences of the osmotic second virial coefficients $A_{2}$ for the mixtures of polystyrene (PSt) and poly ( $p$-chlorostyrene) (PClSt) and for the block copolymers of ABA and BAB types (A, PSt; B, PClSt) were studied in toluene, 2-butanone (MEK), and cumene solutions. All the samples were prepared by anionic polymerization and they are close in molecular weight which is $c a .35 \times 10^{4}$. It was found that in toluene and MEK, plots of $A_{2} v s$. composition obtained for the polymer mixtures and for the block copolymers of ABA and BAB types fell on a single curve in the respective solvents, whereas in the selective solvent, cumene, $A_{2}$ value of the polymer mixtures was smaller than that of the block copolymers with the same composition. The thermodynamic interaction parameter $\chi_{\mathrm{AB}}$ between PSt and PCISt was estimated from $A_{2}$ data, according to the theories of dilute polymer solutions; the $\chi_{\mathrm{AB}}$ values obtained from $A_{2}$ for the ternary system of PSt-PCISt-solvent were 0.086 (in toluene) and 0.063 (in MEK), and those from $A_{2}$ for the block copolymer solutions were 0.076 (in toluene), 0.064 (in MEK) and 0.063 (in cumene). $\chi_{\mathrm{AB}}=0.070 \pm 0.016$ was obtained as the average.

KEY WORDS Interaction Parameter / Polystyrene / Poly ( $p$-chlorostyrene) / Styrene- $p$-Chlorostyrene Triblock Copolymer / Ternary System / Osmotic 2nd Virial Coefficient / Composition Dependence / Dilute Solution /
\end{abstract}

It has been known that diblock and triblock copolymers composed of a pair of incompatible homopolymers exhibit intra-chain phase separation because of repulsive interactions between unlike blocks giving rise to multiphase structures in solid state ${ }^{1 \mathrm{a}, \mathrm{c}}$ In the study of solution properties of block copolymers, the great attention has been concentrated on the question of segregation of blocks of different chemical species in recent years. ${ }^{1 \mathbf{b}, \mathbf{d}}$ If such segregation of blocks occurred in a block copolymer in solution, its conformation could not be approximated with a random coil model.

We have previously investigated the conformational behavior of the styrene-p-chlorostyrene ( $\mathrm{St}-\mathrm{ClSt})$ triblock copolymers in several solvents ${ }^{2}$ and obtained the results leading to a conclusion that procedures and theories originally developed for homopolymer solutions are applicable to the $\mathrm{St}-\mathrm{ClSt}$ block copolymers in non-selective solvents such as toluene and 2-butanone (MEK) and their conformations in these solvents could be approximated with a statistical random coil form. ${ }^{2 a, b, d}$ However, the results obtained for the St-ClSt block copolymers in a selective solvent such as cumene were less conclusive $^{2 a, b, d}$ and it was suggested that the conformation in cumene may change from a random coil form to a segregated form by lowering the temperature..$^{2 c, e}$

Investigation of interactions between component homopolymers can lead to a better understanding of the properties of block copolymers. In this paper, in order to estimate 
the interaction parameter $\chi_{\mathrm{AB}}$ between PSt and PCISt, the composition dependences of osmotic second virial coefficients $A_{2}$ were studied on the mixtures of polystyrene (PSt) and poly( $p$-chlorostyrene) (PClSt) in toluene, MEK and cumene, and also on the St-ClSt triblock copolymer solutions.

\section{EXPERIMENTAL}

\section{Materials}

PSt, PClSt, and the St-ClSt triblock copolymers were prepared by the anionic polymerization technique; polymerization was carried out in tetrahydrofuran at $-78^{\circ} \mathrm{C}$ under $10^{-6} \mathrm{mmHg}$, using sodium naphthalene as the initiator. ${ }^{2 a}$ The products were purified by fractional precipitation from benzene/ methanol. The gel permeation chromatography analysis showed that the molecular weight distribution of the polymer samples was narrow. The composition of the block copolymers was determined by analysis of chlorine. The characteristics of the samples are shown in Table I.

\section{Measurements}

Osmotic pressures $\pi$ for PSt, PCISt, the PSt-PClSt mixtures and the $\mathrm{St}-\mathrm{ClSt}$ block copolymers were measured in toluene and MEK at $30.0^{\circ} \mathrm{C}$ and in cumene at $55.0^{\circ} \mathrm{C}$, using a Hewlett-Packard high speed membrane osmometer Model 502. The second virial coefficient, $A_{2}$, was obtained according to the following equation, ${ }^{3}$

$$
(\pi / c)^{1 / 2}=\left(R T / \bar{M}_{n}\right)^{1 / 2}\left(1+\bar{M}_{n} A_{2} c / 2\right)
$$

where $c$ is the concentration $\left(\mathrm{g} \mathrm{dl}^{-1}\right), \bar{M}_{n}$ is the number average molecular weight, $R$ is the gas constant and $T$ is the absolute temperature.

Viscosities of PSt, PClSt, and the St-ClSt block copolymers were measured using Ubbelohde dilution viscometers with negligible kinetic energy corrections. Intrinsic viscosities $[\eta]$ were determined according to Huggins' equation, ${ }^{4}$ which were shown in Table I.

The partial specific volumes $\bar{v}_{\mathrm{p}}$ of PSt and $\mathrm{PClSt}$ in the three solvents were determined from density measurements by an Anton-Paar Density Meter Model DMA-50. The results are as follows.

\begin{tabular}{lccc}
\hline & \multicolumn{3}{c}{$\bar{v}_{\mathrm{p}} / \mathrm{cm}^{3} \mathrm{~g}^{-1}$} \\
\cline { 2 - 4 } & $\begin{array}{c}\text { Toluene } \\
\left(30.0^{\circ} \mathrm{C}\right)\end{array}$ & $\begin{array}{c}\text { MEK } \\
\left(30.0^{\circ} \mathrm{C}\right)\end{array}$ & $\begin{array}{c}\text { Cumene } \\
\left(55.0^{\circ} \mathrm{C}\right)\end{array}$ \\
\hline PSt & 0.914 & 0.905 & 0.937 \\
PClSt & 0.778 & 0.770 & 0.788 \\
\hline
\end{tabular}

Table I. Characteristics of PSt, PClSt, and the St-ClSt block copolymers ${ }^{\mathrm{a}}$

\begin{tabular}{lccccc}
\hline & & & & & \\
Sample & $\begin{array}{c}\text { Composition } \\
\text { St mol. frac. }\end{array}$ & $\bar{M}_{n} \times 10^{-4}$ & \\
\cline { 3 - 6 } & & & $\begin{array}{c}\text { Toluene } \\
\left(30.0^{\circ} \mathrm{C}\right)\end{array}$ & $\begin{array}{c}\text { MEK } \\
\left(30.0^{\circ} \mathrm{C}\right)\end{array}$ & $\begin{array}{c}\text { Cumene } \\
\left(55.0^{\circ} \mathrm{C}\right)\end{array}$ \\
\hline PSt & 1.000 & 34.1 & 1.284 & 0.688 & 1.137 \\
PClSt & 0.000 & 33.0 & 0.557 & 0.603 & 0.354 \\
BAB-1 & 0.650 & 37.9 & 1.249 & 0.874 & 1.017 \\
BAB-2 & 0.467 & 32.5 & 0.958 & 0.737 & 0.773 \\
BAB-3 & 0.372 & 36.8 & 1.003 & 0.811 & 0.770 \\
ABA-1 & 0.655 & 37.4 & 1.279 & 0.824 & 1.074 \\
ABA-2 & 0.509 & 35.6 & 1.106 & 0.834 & 0.937 \\
ABA-3 & 0.311 & 29.9 & 0.887 & 0.723 & 0.714 \\
\hline
\end{tabular}

a $\mathrm{BAB}$ and $\mathrm{ABA}$ are the St-ClSt block copolymers (A, PSt; B, PClSt). 
Interaction Parameter between PSt and PCISt in Solutions

Table II. Second virial coefficients $A_{2}$ for the ternary systems and polymer-solvent interaction parameter $\chi$ of PSt and $\mathrm{PClSt}^{\mathrm{a}}$

\begin{tabular}{|c|c|c|c|c|c|c|c|}
\hline \multirow{2}{*}{ Sample } & \multirow{2}{*}{$\begin{array}{l}\text { Composition } \\
\text { St. wt. frac. }\end{array}$} & \multicolumn{3}{|c|}{$A_{2} \times 10^{4} / \mathrm{cm}^{3} \mathrm{~mol} \mathrm{~g}^{-2}$} & \multicolumn{3}{|c|}{$\chi$} \\
\hline & & Toluene & MEK & Cumene & Toluene & MEK & Cumene \\
\hline \multirow{7}{*}{$\begin{array}{l}\text { PSt } \\
\text { PClSt } \\
\text { PSt-PClSt } \\
\quad \text { mixture }\end{array}$} & 1.000 & 3.73 & 1.15 & 2.90 & 0.371 & 0.478 & 0.379 \\
\hline & 0.000 & 1.20 & 1.72 & $-0.20_{3}$ & 0.460 & 0.447 & 0.505 \\
\hline & 0.786 & 3.41 & 1.51 & 2.38 & \multicolumn{3}{|c|}{$\left(A_{2}\right)_{\mathrm{AB}} \times 10^{4} / \mathrm{cm}^{3} \mathrm{~mol} \mathrm{~g}^{-2}$} \\
\hline & 0.593 & 2.99 & 1.70 & 1.92 & & & \\
\hline & 0.434 & 2.64 & 1.78 & 1.39 & Toluene & MEK & Cumene \\
\hline & 0.272 & 2.30 & 1.76 & $0.84_{0}$ & & & \\
\hline & 0.133 & 1.75 & 1.82 & $0.37_{8}$ & $3.19 \pm 0.08$ & $2.05 \pm 0.06$ & $(2.65 \pm 0.07)^{\mathrm{b}}$ \\
\hline
\end{tabular}

a Measurements were made in toluene and MEK at $30.0^{\circ} \mathrm{C}$ and in cumene at $55.0^{\circ} \mathrm{C}$.

b Calculated from eq 2 using $A_{2}$ data for the BAB copolymers.

Table III. Second virial coefficients $A_{2}$ and the interaction parameters $\chi_{\text {cop }}$ for the St-ClSt block copolymers ${ }^{\mathrm{a}}$

\begin{tabular}{|c|c|c|c|c|c|c|}
\hline \multirow{2}{*}{ Sample } & \multicolumn{3}{|c|}{$A_{2} \times 10^{4} / \mathrm{cm}^{3} \mathrm{~mol} \mathrm{~g}^{-2}$} & \multicolumn{3}{|c|}{$\chi_{\text {cop }}$} \\
\hline & Toluene & MEK & Cumene & Toluene & MEK & Cumene \\
\hline BAB-1 & 3.02 & 1.68 & 2.19 & 0.383 & 0.453 & 0.398 \\
\hline BAB-2 & 2.62 & 1.78 & 1.65 & 0.400 & 0.449 & 0.425 \\
\hline BAB-3 & 2.23 & 1.75 & 1.37 & 0.411 & 0.446 & 0.438 \\
\hline ABA-1 & 3.00 & 1.68 & 2.27 & 0.382 & 0.455 & - \\
\hline ABA-2 & 2.73 & 1.82 & 1.85 & 0.392 & 0.446 & - \\
\hline ABA-3 & 2.14 & 1.85 & 1.52 & 0.415 & 0.443 & - \\
\hline
\end{tabular}

${ }^{\text {a }}$ Measurements were made in toluene and $\mathrm{MEK}$ at $30.0^{\circ} \mathrm{C}$ and in cumene at $55.0^{\circ} \mathrm{C}$.

\section{RESULTS AND DISCUSSION}

\section{Composition Dependences of $A_{2}$}

The second virial coefficients, $A_{2}$, for the PSt-PClSt mixtures and the St-ClSt block copolymers of $\mathrm{ABA}$ and $\mathrm{BAB}$ types were measured in toluene and $\mathrm{MEK}$ at $30.0^{\circ} \mathrm{C}$, and in cumene at $55.0^{\circ} \mathrm{C}$, which are given in Tables II and III. The solvents chosen for this study are different in a nature towards the homopolymers of two components. Thus, toluene is a good solvent for PSt but a rather moderate solvent for PCISt; MEK is a moderate solvent for both of PSt and PCISt; cumene is good for PSt but poor for PClSt $\left(\theta=59.0^{\circ} \mathrm{C}^{5}\right)$.

The second virial coefficient $A_{2}$ for the ternary system of A polymer-B polymer- solvent can be expressed as functions of composition by the following equation ${ }^{6}$

$$
A_{2}=w_{\mathrm{A}}^{2}\left(A_{2}\right)_{\mathrm{AA}}+w_{\mathrm{B}}^{2}\left(A_{2}\right)_{\mathrm{BB}}+2 w_{\mathrm{A}} w_{\mathrm{B}}\left(A_{2}\right)_{\mathrm{AB}}
$$

where $w_{\mathrm{A}}$ and $w_{\mathrm{B}}$ are the weight fractions of $\mathrm{A}$ and $\mathrm{B}$ in the polymer mixtures, $\left(A_{2}\right)_{\mathrm{AA}}$ and $\left(A_{2}\right)_{\mathrm{BB}}$ are the $A_{2}$ for the homopolymers of $\mathrm{A}$ and $\mathrm{B}$, and $\left(A_{2}\right)_{\mathrm{AB}}$ means the $A_{2}$ corresponding to the interactions between $\mathrm{A}$ and $\mathrm{B}$ polymer chains in the given solvent. In eq 2 , it is assumed that extents of contributions of $\mathrm{A}-\mathrm{A}$, $\mathrm{B}-\mathrm{B}$, and $\mathrm{A}-\mathrm{B}$ interactions can be represented as a product of weight fractions. This assumption will be adequate if a distribution of segments of two polymers is statistically random in the given solvent.

Figures $1-3$ show the $A_{2}$ data presented as 


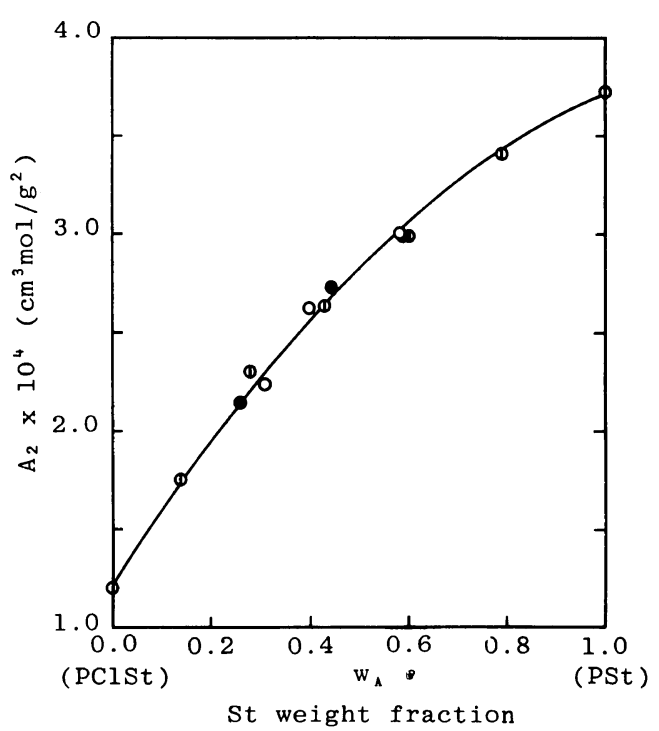

Figure 1. Composition dependences of second virial coefficients $A_{2}$ for the PSt-PCISt mixtures and the StClSt block copolymers in toluene at $30.0^{\circ} \mathrm{C}$. (1), the PSt-PClSt mixtures; $(\bigcirc)$, the ABA copolymer; $(\bigcirc)$, the BAB copolymer; (-), values calculated from eq 2 .

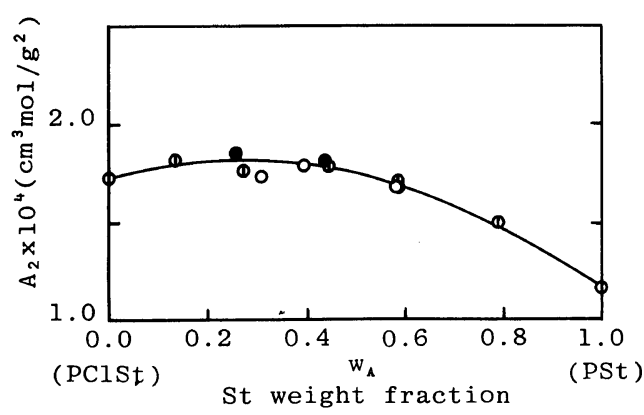

Figure 2. Composition dependences of second virial coefficients $A_{2}$ for the PSt-PClSt mixtures and the St$\mathrm{ClSt}$ block copolymers in MEK at $30.0^{\circ} \mathrm{C}$. Symbols same as in Figure 1.

functions of composition. Molecular weights of all the samples used for the measurements are close enough so that the relatively minor dependence of $A_{2}$ on $\bar{M}_{n}$ can be ignored. It was found that in toluene and MEK solutions, plots of $A_{2} v s$. composition obtained for the polymer mixtures and for the block copolymers of $\mathrm{ABA}$ and $\mathrm{BAB}$ types fitted in a single curve. Such results suggest that the conformations of PSt and PClSt block chains in the

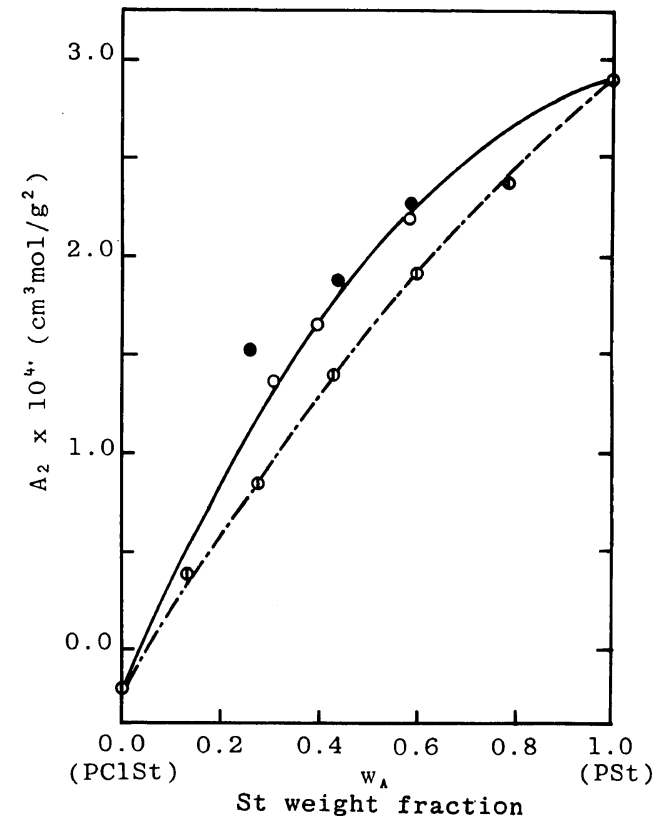

Figure 3. Composition dependences of second virial coefficients $A_{2}$ for the PSt-PCISt mixtures and the St$\mathrm{ClSt}$ block copolymers in cumene at $55.0^{\circ} \mathrm{C}$. (---), experimental fit to the data. Symbols same as in Figure 1.

respective types of the copolymers are similar to those of PSt and PCISt chains respectively in the polymer mixture solutions. This supports our previous conclusion that the conformations of the St-ClSt block copolymers of $\mathrm{ABA}$ and $\mathrm{BAB}$ types in toluene and MEK could be approximated with a random coil form in which domains of unlike segments overlap to a great extent allowing heterocontacts. $^{2 a, b, d}$ In such cases, eq 2 could be applicable to express $A_{2}$ 's for the block copolymers as well as for the polymer mixtures. On the other hand, the results obtained in cumene were different from those in toluene and MEK. In Figure 3, it was noted that plots of $A_{2} v s$. composition for the respective types of the block copolymers and for the polymer mixtures obtained in cumene could be expressed by two separate curves but not a single one; the value of $A_{2}$ for the polymer mixtures was smaller than that for the block copolymers with the same composition. It is supposed in 
cumene, that PClSt chain is rather shrunk whereas PSt chain takes a more extended conformation and domains of PSt and PClSt chains are less overlapped, which makes A-B contacts few. This trend should be higher in the polymer mixtures than in the block copolymers. This may be a cause that the value of $A_{2}$ for the polymer mixtures in cumene was smaller. Plots of $A_{2} v s$. composition for the ABA copolymers were rather scattered, especially for the sample of the highest CISt content. Our previous studies showed that conformational anomaliès may occur for the block copolymers in cumene depending on composition and type of the copolymers, and temperature, and such anomalies are more likely to occur for the $\mathrm{ABA}$ copolymers than for the $\mathrm{BAB}$ copolymers, and also for the copolymers with higher ClSt contents. ${ }^{2 c}$ The anomalies might be caused by intra- and intermolecular associations in the block copolymer solution and in such a case, the assumption of a random distribution of the segments could not be valid. This should be a cause of the scatter of $A_{2}$ data for the ABA copolymers. Thus, eq 2 should not be a good approximation for the polymer mixtures and for the ABA copolymers.

\section{Polymer-Solvent Interaction Parameter}

According to theories of dilute polymer solutions, $A_{2}$ is generally given by the following equation relating to the thermodynamic interaction parameter $\chi$ of a polymer with a solvent,

$$
A_{2}=\left(\bar{v}_{\mathrm{p}}^{2} / V_{\mathrm{s}}\right)\left(\frac{1}{2}-\chi\right) h\left(z / \alpha^{3}\right)
$$

with

$$
z=\left(3 / 2 \pi\left\langle r_{0}^{2}\right\rangle\right)^{3 / 2} \beta n^{2}
$$

where $V_{\mathrm{s}}$ is the molar volume of the solvent, $\left\langle r_{0}^{2}\right\rangle$ is the unperturbed mean square end-toend distance of the polymer, $\beta$ is the excluded volume, $n$ is the number of segments in a chain and $\alpha$ is the expansion factor related to the statistical radius. Several forms of $\alpha(z)$ consistent with $h\left(z / \alpha^{3}\right)$ have been reported. Equations proposed by Kurata-Yamakawa and by Yamakawa-Tanaka are as follows ${ }^{7}$

$$
\begin{aligned}
& h\left(z / \alpha^{3}\right) \\
& \quad=0.547\left[1-\left(1+3.903 z / \alpha^{3}\right)^{-0.4683}\right] /\left(z / \alpha^{3}\right)
\end{aligned}
$$

and

$$
\alpha^{2}=0.541+0.459(1+6.04 z)^{0.46}
$$

We obtained the viscosity-radius expansion factor $\alpha_{\eta}$ from viscosity data in Table I and $[\eta]_{\theta}$ values previously determined. ${ }^{8}$ Thus, the statistical-radius expansion factor $\alpha$ was calculated from the $z$ value obtained by using the relation, ${ }^{7} \alpha_{\eta}^{3}=1.05+0.87 z$.

By applying the relations 3 to 5 to $A_{2}$ data, the interaction parameters of PSt and PClSt with toluene, MEK and cumene were estimated, which are given in Table II. The values of $\chi$ obtained from PSt and PCISt in toluene are 0.371 and 0.460 , respectively. They are close to the values of 0.383 (PSt) and 0.483 (PClSt) which were previously estimated by Ogino et al. ${ }^{9}$ from $A_{2}$ data.

\section{Polymer-Polymer Interaction Parameter}

The interaction parameter $\chi_{\mathrm{AB}}$ between PSt and PClSt was estimated in two different ways. The first one is an estimation from $A_{2}$ for the ternary system of PSt-PCISt-solvent and the second, from $A_{2}$ for the block copolymers in solution.

According to Krigbaum-Flory, $\left(A_{2}\right)_{i j}$ in eq 2 for the A polymer-B polymer-solvent ternary system is expressed as follows ${ }^{10}$

$$
\begin{array}{r}
\left(A_{2}\right)_{i j}=\frac{\bar{v}_{i} \bar{v}_{j}}{2 V_{\mathrm{s}}}\left(1-\chi_{i \mathrm{~s}}-\chi_{j \mathrm{~s}}+\chi_{i j}\right) h\left(z_{i j} / \alpha_{i j}^{3}\right) \\
\left(\chi_{i i}=0\right) \quad(i, j=\mathrm{A} \text { or B })
\end{array}
$$

and then

$$
\begin{aligned}
& \left(A_{2}\right)_{\mathrm{AA}}=\frac{\bar{v}_{\mathrm{A}}^{2}}{V_{\mathrm{s}}}\left(\frac{1}{2}-\chi_{\mathrm{AS}}\right) h\left(z_{\mathrm{AA}} / \alpha_{\mathrm{AA}}^{3}\right) \\
& \left(A_{2}\right)_{\mathrm{BB}}=\frac{\bar{v}_{\mathrm{B}}^{2}}{V_{\mathrm{s}}}\left(\frac{1}{2}-\chi_{\mathrm{BS}}\right) h\left(z_{\mathrm{BB}} / \alpha_{\mathrm{BB}}^{3}\right)
\end{aligned}
$$




$$
\left(A_{2}\right)_{\mathrm{AB}}=\frac{\bar{v}_{\mathrm{A}} \bar{v}_{\mathrm{B}}}{2 V_{\mathrm{s}}}\left(1-\chi_{\mathrm{AS}}-\chi_{\mathrm{BS}}+\chi_{\mathrm{AB}}\right) h\left(z_{\mathrm{AB}} / \alpha_{\mathrm{AB}}^{3}\right)
$$

where $\bar{v}_{\mathrm{A}}$ and $\bar{v}_{\mathrm{B}}$ are the partial specific volumes for the homopolymers, $\mathrm{A}$ and $\mathrm{B}, \chi_{\mathrm{AS}}$ and $\chi_{\mathrm{BS}}$ are the interaction parameters for the homopolymers of $\mathrm{A}$ and $\mathrm{B}$, respectively with solvent, and $\alpha_{\mathrm{AB}}$ and $z_{\mathrm{AB}}$ are the quantities related to the interactions between $\mathrm{A}$ and $\mathrm{B}$ polymers in the given solvent.

The interaction parameter $\chi_{\mathrm{AB}}$ can be estimated from $\left(A_{2}\right)_{\mathrm{AB}}$ by using eq $6 \mathrm{c}$, provided that the value of $h\left(z_{\mathrm{AB}} / \alpha_{\mathrm{AB}}^{3}\right)$ is known. An estimation of $h\left(z_{\mathrm{AB}} / \alpha_{\mathrm{AB}}^{3}\right)$ is rather a problem and it involves a fundamental difficulty. Our estimation at present was carried out as follows. Values of $z$ for copolymers, $z_{\text {cop }}$, were estimated from $\alpha_{\eta}$ by the relation used for the case of homopolymers. ${ }^{11}$ Then, the $z_{\mathrm{AB}}$ values were calculated using $z_{\text {cop }}$ values for the copolymers, $z_{\mathrm{AA}}$ for PSt and $z_{\mathrm{BB}}$ for PCISt, according to the following equation given by Benoit et al., ${ }^{12}$

$$
z_{\text {cop }}=x_{\mathrm{A}}^{2} z_{\mathrm{AA}}+x_{\mathrm{B}}^{2} Z_{\mathrm{BB}}+2 x_{\mathrm{A}} x_{\mathrm{B}} z_{\mathrm{AB}}
$$

where $x_{\mathrm{A}}$ and $x_{\mathrm{B}}$ are the mole fractions of $\mathrm{A}$ and $\mathrm{B}$, respectively, in the copolymers. And then, the values of $h\left(z_{\mathrm{AB}} / \alpha_{\mathrm{AB}}^{3}\right)$ in eq $6 \mathrm{c}$ were evaluated by combining eq 4 and 5 using the $z_{\mathrm{AB}}$ values obtained.

As already pointed out, eq 2 could be applicable to $A_{2}$ data for the PSt-PCISt mixtures in toluene and MEK but not to those in cumene. The values of $\left(A_{2}\right)_{\mathrm{AB}}$ in toluene and MEK were determined by applying eq 2 to all $A_{2}$ data by a least square method. The results are shown in Table II. The values of $\chi_{\mathrm{AB}}$ estimated from these values by using eq 4 to 7 are given in Table IV.

The interaction parameter $\chi_{\text {cop }}$ of the block copolymers with solvents can be evaluated if the relations 3 to 5 could apply to $A_{2}$ data obtained for the block copolymers. An evaluation of $\chi_{\text {cop }}$ was attempted by using the same procedures as used for the homopolymer solutions and the results are given in Table III.

For the interaction parameter $\chi_{\text {cop }}$ of a binary copolymer with a solvent, Stockmayer et al. proposed the following equation ${ }^{13}$

$$
\chi_{\text {cop }}=x_{\mathrm{A}} \chi_{\mathrm{AS}}+x_{\mathrm{B}} \chi_{\mathrm{BS}}-x_{\mathrm{A}} x_{\mathrm{B}} \chi_{\mathrm{AB}}
$$

which assumes that (a) the distribution of segments of two components $\mathrm{A}$ and $\mathrm{B}$ in solution is statistically random; (b) solvent molecules and both kinds of monomer units have the same volume. The assumption (a) will not be so erroneous for the block copolymers in toluene and MEK but (b) should be invalid as it is generally not correct. Nevertheless, it was found that eq 8 can adequately express the experimental values of $\chi_{\text {cop }}$ as a function of composition; the $\chi_{\mathrm{AB}}$ value determined from eq 8 were independent of composition, and the curve calculated by inserting this $\chi_{\mathrm{AB}}$ value

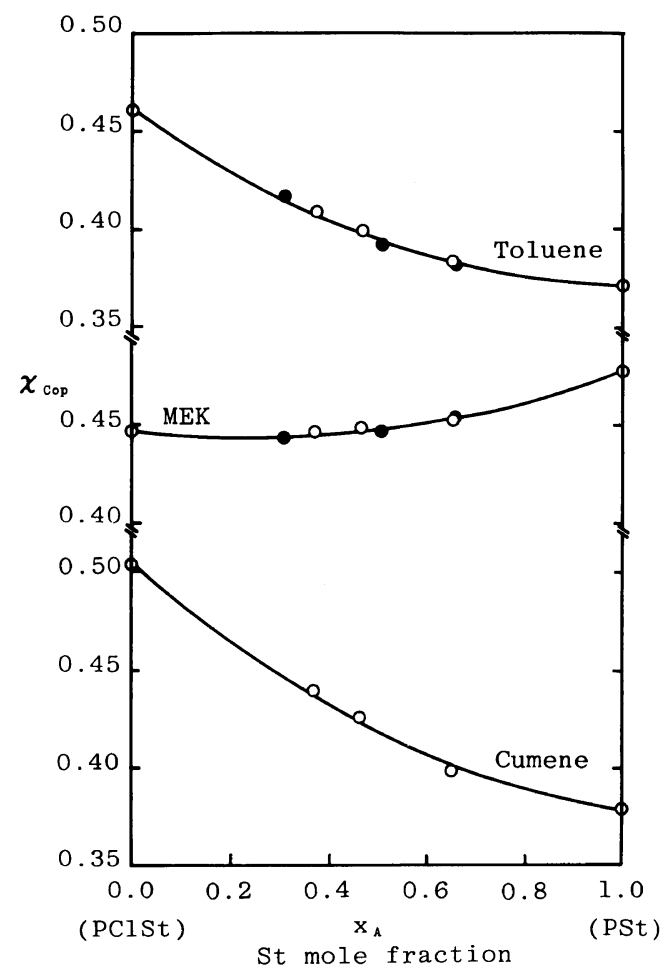

Figure 4. Plots of the interaction parameter $\chi_{\text {cop }}$ vs. composition for the St-ClSt block copolymers. (-), values calculated from eq 8 . Symbols are same in Figure 1. 
Table IV. The interaction parameter $\chi_{\mathrm{AB}}$ between .PSt and PClSt

\begin{tabular}{clcc}
\hline & & \multicolumn{2}{c}{$\chi_{\mathrm{AB}}$} \\
\cline { 3 - 4 } Method & Solvent & \multicolumn{2}{c}{ Average } \\
\hline \multirow{2}{*}{$\begin{array}{c}\text { From osmotic 2nd virial coefficients, } A_{2} \\
\text { Ternary system }\end{array}$} & Toluene & 0.086 & \\
& MEK & 0.063 & \\
& Cumene & - & $0.070 \pm 0.016$ \\
Block copolymer & Toluene & 0.076 & 0.070 \\
& MEK & 0.064 & \\
& Cumene & 0.063 & \\
& & &
\end{tabular}

From intrinsic viscosities, $[\eta]$

Block copolymer Toluene 0.098

MEK 0.075

$0.087 \pm 0.012$

From solubility parameters, $\delta$

- $\quad 0.06$

into eq 8 showed a reasonably good agreement with the experimental values of $\chi_{\text {cop }}$ as shown in Figure 4. The values of $\chi_{\mathrm{AB}}$ determined from $\chi_{\text {cop }}$ in the three solvents, toluene, MEK and cumene, are shown in Table IV.

In the estimations of $\chi_{\mathrm{AB}}, V_{\mathrm{s}}$ in eq 3 and 6 was assumed as $100\left(\mathrm{~cm}^{3}\right)$ instead of employing molar volumes of the respective solvents, since $\chi_{\mathrm{AB}}$ should be different in each of the solutions depending on the solvent only through its molar volume if we use molar volumes of each solvent for $V_{\mathrm{s}}, 107.5\left(\mathrm{~cm}^{3}\right)$ for toluene, $90.8\left(\mathrm{~cm}^{3}\right)$ for MEK and $144.5\left(\mathrm{~cm}^{3}\right)$ for cumene.

In Table IV, it is noted that an agreement between the $\chi_{\mathrm{AB}}$ values obtained from $A_{2}$ for the polymer mixture solutions and those from $\chi_{\text {cop }}$ for the block copolymer solutions was rather satisfactory, while there are some discrepancies between the $\chi_{\mathrm{AB}}$ value obtained in toluene and that in MEK and cumene. Comparing with toluene and cumene, MEK should be a more favorable solvent for estimating $\chi_{\mathrm{AB}}$ from $A_{2}$ of the PSt-PClSt mixtures since MEK has a similar nature towards PSt and PClSt, ${ }^{14}$ i.e., $\chi_{\mathrm{AS}}=0.478$ and $\chi_{\mathrm{BS}}=0.447$, and the assumptions in eq 2 and 8 will be better approximations for the PSt-PClSt-
MEK system than for the PSt-PClSt-toluene system, which may lead to a conclusion that the $\chi_{\mathrm{AB}}$ value in MEK will be more reliable than that in toluene and cumene. However, we have to take accounts of some other causes producing the discrepancies among the figures of $\chi_{\mathrm{AB}}$. Experimental inaccuracies in determining $A_{2}$ are naturally a cause of them and besides, an uncertainty in the $h\left(z / \alpha^{3}\right)$ values would be more significant, and an error in $\chi_{\text {cop }}$ produces a rather great difference in $\chi_{\mathrm{AB}}$. Moreover, theoretical limitations of the procedures also cause an uncertainty of $\chi_{\mathrm{AB}}$. From these points of view, it is hard to say which is a better value for $\chi_{\mathrm{AB}} \cdot \chi_{\mathrm{AB}}=0.070 \pm$ 0.016 was obtained as the average.

For the purpose of comparison, $\chi_{\mathrm{AB}}$ values evaluated from intrinsic viscosities are also shown in Table IV. These values were obtained using our previous data ${ }^{2 b}$ by assuming the following equation for the excluded volume parameter $\beta_{\text {cop }}$ for the block copolymers, ${ }^{2 b}$ which is equivalent of eq 8 for $\chi_{\text {cop }}$ and has the same limitations,

$$
\beta_{\text {cop }}=x_{\mathrm{A}} \beta_{\mathrm{AA}}+x_{\mathrm{B}} \beta_{\mathrm{BB}}+2 x_{\mathrm{A}} x_{\mathrm{B}} \Delta \beta_{\mathrm{AB}}
$$

with

$$
\Delta \beta_{\mathrm{AB}}=\beta_{\mathrm{AB}}-\left(\beta_{\mathrm{AA}}+\beta_{\mathrm{BB}}\right) / 2
$$

where $\beta_{\mathrm{AA}}, \beta_{\mathrm{BB}}$, and $\beta_{\mathrm{AB}}$ are the parameters characterizing $\mathrm{A}-\mathrm{A}, \mathrm{B}-\mathrm{B}$, and $\mathrm{A}-\mathrm{B}$ interactions in the given solvent. $\Delta \beta_{\mathrm{AB}}$ is related to $\chi_{\mathrm{AB}}$ by the equation

$$
\Delta \beta_{\mathrm{AB}}=\left(V_{\mathrm{s}} / N\right) \chi_{\mathrm{AB}}
$$

where $N$ is Avogadro number.

The $\chi_{\mathrm{AB}}$ value in the last row in Table IV is that calculated from the Hildebrand-Scott solubility parameters, $\delta_{\mathrm{A}}$ for PSt and $\delta_{\mathrm{B}}$ for PClSt. By assuming that polymer-polymer interaction is mostly enthalpic rather than entropic, $\chi_{\mathrm{AB}}$ could be expressed as ${ }^{15}$

$$
\chi_{\mathrm{AB}}=\frac{V_{\mathrm{r}}}{R T}\left(\delta_{\mathrm{A}}-\delta_{\mathrm{B}}\right)^{2}
$$

where $V_{\mathrm{r}}$ is a reference volume. Equation 
11, with the solubility parameters of 9.03 $\left(\mathrm{cal} \mathrm{cm}^{-3}\right.$ ) for PSt and $9.63\left(\mathrm{cal} \mathrm{cm}^{-3}\right)^{1 / 2}$ for PClSt, $V_{\mathrm{r}}=100\left(\mathrm{~cm}^{3}\right)$ and $T=298 \mathrm{~K}$ gives $\chi_{\mathrm{AB}}=0.061,{ }^{16}$ which is rather in a good agreement with the experimental $\chi_{\mathrm{AB}}$ value obtained in MEK and cumene solutions from this study.

\section{REFERENCES}

1. (a) J. V. Dawkins, "Block Copolymers," D. C. Allport and W. H. Janes, Ed., Applied Science, London, 1973, Chapter 8; (b) ibid., Chapter 9; (c) E. Helfand and Z. R. Wasserman, "Developments in Block Copolymers-1," I. Goodman, Ed., Applied Science, London, 1982, Chapter 4; (d) J. M. G. Cowie, ibid., Chapter 1.

2. (a) M. Shima, E. Ogawa, and K. Konishi, Makromol. Chem., 177, 241 (1976); (b) M. Shima, E. Ogawa, S. Ban, and M. Sato, J. Polym. Sci., Polym. Phys. Ed., 15, 1999 (1977); (c) M. Shima, E. Ogawa, and M. Sato, Polymer, 20, 311 (1979); (d) M. Shima, N. Yamaguchi, M. Sato, and E. Ogawa, Eur. Polym. J., 19, 601 (1983); (e) E. Ogawa and M. Shima, Polym. J., 18, 443 (1986).

3. P. J. Flory, "Principles of Polymer Chemistry," Cornell Univ. Press, Ithaca, New York, 1953, Chapter 7.

4. M. L. Huggins, J. Am. Chem. Soc., 64, 2716 (1942).

5. Y. Izumi and Y. Miyake, Polym. J., 4, 205 (1973).
6. H. Yamakawa, "Modern Theory of Polymer Solutions," Harper \& Row, New York, 1971, Chapter 4.

7. H. Yamakawa, "Modern Theory of Polymer Solutions," Harper \& Row, New York, 1971, Chapter 7.

8. $[\eta]_{\theta}$ values were obtained by using $K_{0}$ values in ref $2 \mathrm{~b}$ according to the relation $[\eta]_{\theta}=K_{0} M^{1 / 2} ;[\eta]_{\theta}=$ 0.479 for PSt and 0.356 for PCISt.

9. K. Kubo and K. Ogino, Bull. Chem. Soc. Jpn., 44, 997 (1971).

10. W. R. Krigbaum and P. J. Flory, J. Chem. Phys., 20, 873 (1952).

11. Values of $\alpha_{\eta}$ for the copolymers were determined from viscosity data in Table $I$ and $[\eta]_{\theta}$ values obtained by using $K_{0}$ values in ref $2 \mathrm{~b}$.

12. D. Froelich and H. Benoit, Makromol. Chem., 92, 224 (1966).

13. W. H. Stockmayer, L. D. Moore, Jr., M. Fixman, and B. N. Epstein, J. Polym. Sci., 16, 517 (1955).

14. (a) L. Zeman and D. Patterson, Macromolecules, 5, 513 (1972); (b) C. C. Hsu and J. M. Prausnitz, ibid., 7, 320 (1974); (c) T. Fukuda, H. Inagaki, and M. Nagata, Polym. Prepr. Jpn., 35, 1058 (1986).

15. (a) J. H. Hildebrand and R. L. Scott, "The Solubility of Nonelectrolytes," Devor Publications Inc., New York, 1964; (b) J. H. Hildebrand and R. L. Scott, "Regular Solutions," Prentice-Hall, Englewood Cliffs, New Jersey, 1962.

16. M. Sato and M. Shima, Sci. Rep. Tokyo Woman's Christian Univ., 33, 691 (1982). 